\title{
An evaluation of clinical governance in the public health departments of the West Midlands Region
}

\author{
A M Hartley, R K Griffiths, K L Saunders
}

J Epidemiol Community Health 2002;56:563-568

See end of article for authors' affiliations

......................

Correspondence to: Dr A M Hartley, Department of Public Health and Epidemiology, University of Birmingham, Edgbaston, Birmingham, B15 2TT, UK.

a.m.hartley@bham.ac.uk.

Accepted for publication 17 December 2001

\begin{abstract}
Study objectives: (1) To evaluate the development of clinical governance within public health departments. (2) To assess two models for examining clinical governance in public health departments.

Design: Semi-structured interviews carried out during the annual visits of the regional director of public health to the health authority public health departments.

Setting: West Midland Region, England.

Participants: Directors of public health plus other members of public health departments.

Main results: These visits demonstrated that there is already a substantial amount of clinical governance activity taking place in the region's public health departments. There was also a need to reclassify many routinely occurring activities and include them under the clinical governance heading.

Conclusions: The two models both proved useful for examining clinical governance in public health departments, however combining them into a matrix provided the best results. This matrix will still be useful after the reorganisation of the NHS and could be used to assess any public health department in the world. The West Midland public health departments find the visits valuable as they provide a source of external peer review of their activities. The public health departments have ownership of the process.
\end{abstract}

$\mathrm{T}$ he Faculty of Public Health Medicine in the UK (FPHM) has described clinical governance as "a framework for improving quality and safeguarding high standards by creating an environment in which excellence will flourish". ${ }^{1}$ Since the introduction of clinical governance in the UK through the white paper The New NHS Modern Dependable ${ }^{2}$ there have been many papers describing initiatives in the clinical setting, but few reported from the setting of public health departments. ${ }^{3}$ However, there have been several publications on components of clinical governance such as audit and quality control and their application to public health departments. ${ }^{4-9}$

Although clinical governance is generally thought of as the province of clinical service providers, it is also essential in public health departments as they are responsible for the population's health. Any failure in performance at public health department level could have much wider consequences than the failure of an individual practitioner. There is therefore a need in public health departments for systems that bridge the gap between individual and corporate governance. Clinical governance is the ideal framework by which to improve the quality of performance of public health departments.

The NHS regional offices (RO) have (until l April 2002) been responsible for ensuring that all clinical governance guidance is implemented in a coherent manner across the regions, and for assessing progress against individual organisation's objectives. ${ }^{10}$ The regional director of public health (RDPH) based at the RO is specifically responsible for the development of the public health function at local level. ${ }^{11}$ The RDPH for the West Midlands Region (WM) has carried out annual visits to health authorities (HAs) in the region since 1994, in order to develop performance within a framework agreed with the directors of public health (DsPH). (The DsPH lead public health departments based in the health authorities, which are responsible for public health in a population of about 400 000). Each year the visit has focused on a different aspect of the departments' performance, including communicable disease control; departmental management; infor- mation technology; and research and publications. In 1999 the visit focused on clinical governance within the public health departments, this was in parallel with an audit of clinical governance within the hospital trusts of the WM, carried out by the public health directorship.

Two models were chosen for the audit of clinical governance in the WM region, one was the FPHM's model described in Governance of the Public Health Function ${ }^{1}$ and the other was a model developed at the NHS WM Regional Office (by R K Griffiths and C Grainger). This model known as "SPOCK" consisted of five main themes: Structure, Process, Outcome, Culture, and Knowledge, which could be further subdivided into topics directly related to clinical governance. The model described by the FPHM ${ }^{1}$ consisted of four levels at which to consider aspects of clinical governance. The four levels are: (a) the individual public health practitioner, (b) departments of public health and other similar groups of public health professionals, (c) health authorities, health boards, and similar organisations and (d) partner organisations, which are referred to in this text as individual, department, organisation, and partners respectively.

\section{METHOD}

The RDPH visited the public health departments of the HAs of the WM region. In preparation for the visits, the departments were provided with copies of the FPHM papers on Governance of the Public Health Function and Revalidation in Public Health Medicine and they were asked to provide the following documentation:

Abbreviations: $\mathrm{HA}$, health authority; RO, regional office; $\mathrm{RDPH}$, regional director of public health; CPD, continuing professional development; PDP, professional development plan; IPR, individual performance review; LA, local authority 
Table 1 An example of the interaction between the West Midlands SPOCK model and the model produced by the Faculty of Public Health Medicine, presented as a matrix

\begin{tabular}{|c|c|c|c|c|}
\hline & Individual & Department & Organisation & Partners \\
\hline Structure & Training & $\begin{array}{l}\text { Business plan } \\
\text { Audit programmes }\end{array}$ & $\begin{array}{l}\text { Position of PH "Key" in } \\
\text { organisation }\end{array}$ & $\begin{array}{l}\text { Joint posts } \\
\text { Joint use of premises }\end{array}$ \\
\hline Process & Individual objectives & $\begin{array}{l}\text { External peer review } \\
\text { Controls assurance }\end{array}$ & Organisational development & Forums and meetings \\
\hline Outcome & Appraisals & Peer review and benchmarking & $\begin{array}{l}\text { Reports to HA } \\
\text { Investors in People }\end{array}$ & Joint achievements \\
\hline Culture & $\begin{array}{l}\text { Induction for new } \\
\text { members of staff }\end{array}$ & Team building & Identified values & Written values and "treaties" \\
\hline Knowledge & CPD & Electronic information systems & $\begin{array}{l}\text { Information management } \\
\text { Library facilities }\end{array}$ & $\begin{array}{l}\text { Shared information systems anc } \\
\text { publications }\end{array}$ \\
\hline
\end{tabular}

- A completed questionnaire about continuing professional development (CPD) in the department. (CPD is a requirement for revalidation of medical practitioners with the General Medical Council.)

- A paper on their approach to clinical governance in public health.

- Any publications of relevance to clinical governance written by any member of the local department in the past year.

- A list of other publications in the past year.

The visit consisted of a semi-structured interview in which clinical governance was discussed in relation to the SPOCK model and FPHM model (see appendix for details of the questionnaire). Notes were taken during the interview and the results were written up in letter form and sent to the departments for verification. The results from the interviews were collated into a matrix for analysis.

\section{RESULTS}

All the departments provided the paperwork as requested, many sending electronic versions of papers posted on the regional internet site (REGINET), one provided all documents on CD ROM. Twelve of the thirteen public health departments were visited during the period October to December 1999 and the thirteenth in April 2000. The number of people present at the interviews varied considerably from two to the whole public health department. In all cases the director of public health (DPH) was present. The interviews lasted approximately 90 minutes.

Table 1 shows the FPHM model combined with the SPOCK model to form a matrix. In each cell there is an example of one of the subjects covered under each of the headings. The results are discussed in more detail below. One general finding was that most departments felt that clinical governance provided a framework to bring a number of existing governance activities into a more coherent whole.

\section{Individual level}

The issues concerning individuals focused mainly on the theme of CPD and professional development plans (PDP), and also on appraisal or individual performance review (IPR), all of which are part of revalidation for medical practitioners in the UK. Appraisal and CPD were generally very well addressed by the departments, with only two departments still in the development stage. Some departments stated that they had CPD for all staff including secretarial and administrative staff. Appraisals were also carried out on all staff, and one department stated that they had produced a handbook on IPR. Appraisal is one of the items emphasised in the FPHM document as important for developing clinical governance at the individual level; it was a subject that was almost universally raised at the meetings. Setting individual objectives during appraisal was also mentioned at some meetings, as encouraged by the FPHM document. The departments arranged induction for new members of staff, some had induction packs for temporary staff, and it was customary for new members of staff to be introduced to the DPH. Other items raised included the inclusion of person specifications and objectives within job descriptions; and events when members of staff introduced their work to the rest of the team.

\section{Department level}

During the interviews the majority of the discussion of clinical governance focused on the public health department. These departmental results will be listed under the SPOCK headings for ease of presentation, however these include the FPHM agenda items, as there was considerable overlap between the two schemes. There was much discussion at this level; the breadth of the subject matter and the variety of approaches in the different departments are shown in table 2.

\section{Structure}

The structures developed for clinical governance at the departmental level included the subject of responsibility for clinical governance, and all except one department had clearly allocated this. The resources and training to support clinical governance were also discussed (see table 2), half of the departments reported good resource allocation, and nine reported that they had some training about clinical governance. Meetings were listed as part of the clinical governance structure by the various departments, the business plans and regular departmental meetings also meet the FPHM agenda for developing clinical governance at this level.

\section{Process}

This section of the discussion produced the most information at the department level. The importance of external appraisal for professional development was emphasised by the FPHM, and all departments had developed some form of external assessment. Many of the sources of external peer review (see table 2) were mentioned at more than one HA. All the departments were carrying out audit, and three departments reported that they had become more systematic in their approach to audit in the light of clinical governance. Audit programmes varied in both the frequency (up to seven per year) and the subjects of the audit. A wide variety of controls assurance subjects were discussed (see table 2). Some departments had written protocols, procedures, and terms of reference for their risk management programme. Four departments reported carrying out "postmortems" and incident debriefs after events. Discussions about records and protocols included both the standard and availability of written records, and the extent of written protocols and procedures in place. All departments were working on improving written record keeping, and four departments were 
Table 2 Public Health Departmental level approach to clinical governance using West Midlands SPOCK model

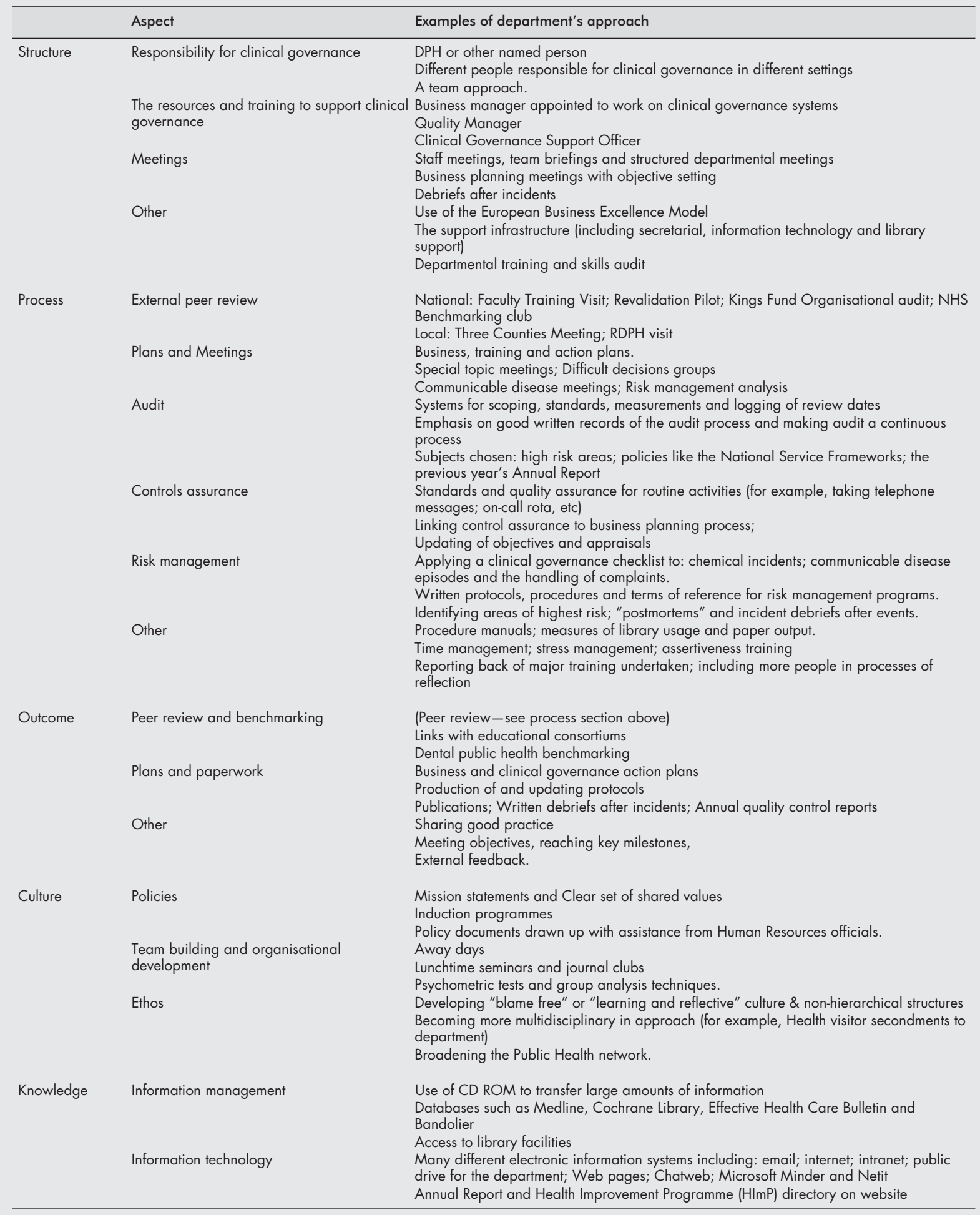

already considered good or excellent at record keeping at the time of the visits.

\section{Outcome}

The main outcomes discussed at the departmental level were peer review, plans and paperwork, and other items such as output from meetings (table 2). Anticipated future outcomes included achieving "Investors in People" (the UK national standard which sets a level of good practice for training and development of people to achieve business goals).

\section{Culture}

At the departmental level the discussion about culture concentrated on policies, team building, organisational development, and the development of ethos. Four departments had already produced a clear set of values while other departments 
had not yet written down their perceived shared values. Team and organisational development also featured on the FPHM agenda, and was discussed at most of the meetings. Team building was a strength in most of the departments, with only two departments still at the development stage. Some departments had used the Myers Briggs Type Indicator (MBTI $)^{12}$ psychometric tests to improve organisational development, while others were considering using either MBTI or other group analysis techniques such as Belbin. ${ }^{13}$

\section{Knowledge}

The departments managed knowledge through a variety of means, however with an emphasis on information technology (IT). All the departments seemed keen to develop user friendly systems providing easy access to circulars, and there was general approval of the idea of developing an Intranet for public health. Access to library facilities varied between departments.

\section{Organisation level}

Clinical governance was also discussed at the organisational level (that is, how it involved the whole health authority). Nine departments indicated that public health had a high profile in the organisation and several departments said public health led on various projects within the HA. Public health departments were accountable to the HA for their performance via the IPR process and the fact that outputs from the directorate were shown to the chief executive. One department presented epidemiological reviews to the HA on a two monthly basis.

At the HA level, there was development of organisational risk management, frameworks for controls assurance, and discussions by directors on standards. The public health departments were involved in working with Trust directors and organising clinical governance visits; and they were also involved in complaints procedures when required. One of the departments had appointed a clinical governance support officer who also worked on clinical governance in the HA.

The general discussion covered the idea that the public health business plan should be developed to link into the organisation's overall aims and objectives, and one DPH reported that the public health training plan was being developed to feed into the HA planning process. Organisational development was also being considered by HAs including psychometric testing (MBTI/Belbin) and working towards the "Investors in People" award. The FPHM document also emphasised the importance of team and organisational development at this level and the importance of appropriate educational programmes.

The eventual award of "Investors in People" to various HAs was discussed as an organisational outcome. Other possible future outcomes were discussed, and included proactive work to link NHS Direct (a 24 hour telephone help line accessed directly by the general public) and Geographical Information Systems (GIS) to communicable disease surveillance work. When organisational culture was discussed many of the HAs stated that they had identified values. This discussion was similar to that for departmental culture, with the addition of teambuilding for the executive directors.

Knowledge management was handled differently in the various HAs, with some reporting good provision such as a new library, and a full time librarian appointed while others reported difficulty with working across boundaries and against other priorities. One HA had a single information department with a new post jointly funded by the HA, Trust, and Primary Care Group (PCG), another had a "Knowledge net" between HA, PCG, and health community, sign posting best evidence and information sites. Others mentioned developing extranet or intranet links to the PCGs and Trusts.

Some items on the FPHM agenda at the organisational level were not covered in such depth. These included systematic

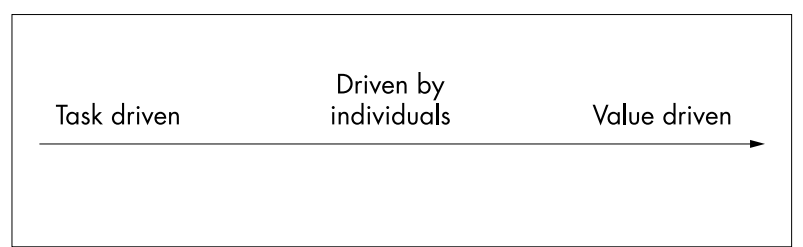

Figure 1 Maturation of partnership development.

review, critical incident reporting and dealing with poor performance, however these had already been discussed at the departmental level.

\section{Partners}

There was a general consensus that partnership working was moving from a task driven to a value driven relationship (see fig 1), though the extent to which this had progressed varied from department to department, with some having more difficulty in forging relationships than others. Six departments felt that they had already developed a value driven relationship. Some partnerships had written values and work programmes, one department had produced constitutions and terms of reference for partnership working. Others had joint posts, joint funding and/or joint budgets for projects, and shared agendas. One of the departments was involved in a formal civic partnership, with a stated vision, and a community plan with five priorities. The civic partnership was an integral part of the health improvement programme and the health action zone implementation plan for that HA.

In several authorities the joint consultants committee (JCC) had been turned into a partnership meeting for example in one HA it had become a health improvement programme (HImP) health focused body, elsewhere it had become a "big picture" group or a partner forum. In one area, the local authority chairs the health forum, and the chief executive of the HA is on the Strategic Regeneration Board. They are developing a "health community" in which health is key in partner relationships. At least one department emphasised the importance of HImPs in moving the partnership culture from task to value driven.

It was noted that local authorities (LAs) and HAs have different cultures, however it was acknowledged that this could be advantageous as it meant exposure to new ideas and ways of working, for example the LA concept of "best value" or their use of the Business Excellence model. Within an individual department there are often different relationships with various partners, for example one department reported that there was a shared vision in mental health and family support partnerships, while the relationship with social services was more task driven. One of the departments commented on the value of receiving positive feedback from partners, for example comments on the annual report from the LA. Other useful outcomes were that the partners were able to use each other's premises for meetings, etc.

There was some discussion about the legal duty of partnership in the Health Act $1999{ }^{14}$ as this may effect many aspects of working together, including the sharing of information and financial arrangements, which have yet to be fully explored. Other discussion involved the development of youth strategy with partner organisations.

\section{DISCUSSION}

There was wide variety of response to clinical governance from the public health departments. As anticipated when using semi-structured interviews, not all subjects were discussed in all departments to the same depth. This resulted in differing quantities of information recorded in the minutes under the various subheadings. For example, while audit and the electronic management of information (IT) were recorded in 


\section{Key points}

- There is currently very little literature about clinical govern ance in the setting of public health departments.

- There is a substantial amount of clinical governance activity taking place in the West Midland region's public health departments.

- A matrix, produced by the combination of two models, proved to be a valuable tool for examining clinical governance in public health departments.

- This matrix will continue to be useful after the reorganisation of public health departments and the formation of strategic health authorities and primary care trusts.

- The matrix is generic and could be used to assess any public health department in any health system.

the minutes for all departments, debriefs after incidents were recorded in 10 of 13 departments, and CPD, appraisal, peer review, and the named person responsible for clinical governance in 9 of 13.

The departments were already addressing issues related to clinical governance, however the RDPH visit provided a focus and opportunity for reflection. It also provided the opportunity for innovations and good practice encountered at the earlier visits to be described and discussed during later visits, leading to the dissemination of good ideas.

As many of the components of clinical governance were already in place, being carried out routinely but under different titles, there was a need to reclassify these activities and include them under the clinical governance heading. These activities included incident debriefs; organisational development; audit; risk management and complaints handling.

There was variation in the progress of development of clinical governance between departments, and some gaps were apparent. Overall there were both strengths and weakness detected during the visits. The strengths included the fact that the internal organisation had improved in the departments since the previous visit, and most departments had a business plan. Also the departments were strong on information management; incident debriefs; and CPD and appraisals. Weaknesses included a tendency to believe that clinical governance was the responsibility of the named person, rather than being the concern of everyone in the department. There was a need for improvement in documentation; procedures for risk management and complaints handling; and few departments appeared to have written value statements or mission statements. Although all departments carried out audit, the subjects were not always chosen systematically, giving a rather haphazard impression, and the audits need to be more coherently captured on paper. When working with partners there was some conflict between the Duty of Partnership ${ }^{14}$ and the issues of confidentiality. ${ }^{15}{ }^{16}$ And finally some departments had difficult relationships with other directorships within the HA or even with the chief executive. One of the useful outcomes of the departmental visits is that these weaknesses can be identified and steps can be taken to remedy them.

The public health departments consider the annual visit of the RDPH to be a useful example of external peer review, in fact some presented the summary letter to their chief executives or HAs. The departments have ownership of the system, as the framework of the visits is agreed in advance by the DsPH. As they were involved in both the design and format of the department visits, and in the choice of subject matter for discussion, they therefore participate in the process rather than having it imposed upon them.

Both the Faculty's model and the West Midlands SPOCK model proved useful in assessing the progress of clinical governance activity in public health departments. The Faculty's model enabled clinical governance to be examined at the various levels of the organisation, whereas the SPOCK model per- mitted many different aspects of clinical governance to be followed up (table 2). The combination of the two models into a matrix (table 1) proved the most useful way of approaching the evaluation of the progress of clinical governance. The matrix can be used, and the results discussed with the department during the visit, without the need for further analysis as it has a very simple design. The matrix could be used as a useful self assessment measure of clinical govenance in any public health department in any setting.

Since these visits took place there have been major changes to the organisation of the NHS in England and Wales following the publication of the governments directive Shifting the Balance of Power in the NHS. ${ }^{17}$ The HAs are being replaced by strategic health authorities (StHAs) and primary care trusts (PCTs). In the West Midlands this means that public health functions will be delivered by approximately 26 PCTs and 3 StHAs in the place of the 13 HAs. During this period of change the need for effective clinical governance becomes even greater, because as public health departments become smaller the public health function may be more vulnerable to eccentric practice. The matrix provides a powerful tool to assist those responsible for the new departments.

\section{Conclusions}

These visits showed that there is already a substantial amount of clinical governance activity taking place in the regions public health departments. It should be acknowledged that many of these activities were being carried out before the advent of clinical governance, however there is also evidence that the departments are also producing new systems.

The two models both proved useful for examining clinical governance in public health departments, however combining them into a matrix provided the best results. The matrix will continue to be useful for public health departments after the reorganisation of the NHS, and could be used in any organisational setting world wide.

The West Midlands public health departments find the visits valuable as they provide a source of external peer review of their activities. The public health departments have ownership of the process.

\section{ACKNOWLEDGEMENTS}

We acknowledge Janet Baker whose MPH project helped to establish the health authority visits, and Caron Grainger who contributed to the SPOCK model.

\section{DEPARTMENT VISITS 1999: STANDARD AGENDA CLINICAL GOVERNANCE AND QUALITY 1 SPOCK}

Structure:

- Who is responsible?

- What are the resources to support it?

- What training is given?

Process:

- How can you tell what you are doing?

- Audit and risk management

- Incident de-briefs?

- Handling of complaints

- How do you decide what to audit?

- Record keeping

Outcome:

- Peer review/external visitors to assess how doing?

Culture:

- Is there a statement of values?

- Induction programmes?

- Team building events? 
Knowledge:

- How do you manage knowledge?

- Use of intranet?

- How do you use information strategically?

\section{Faculty Framework}

Individual practitioner-CPD and wider personal development

Department-team development; problem solving; where do the "gold stars" come from? Any peer review?

Organisational level—accountability to HA

Partners-shared values or task driven

3 Public Health Capacity

Are there people in partner organisations to develop into public health specialists?

\section{Publication}

\section{Authors' affiliations}

A M Hartley, Department of Public Health and Epidemiology, University of Birmingham, Edgbaston, Birmingham, UK

R K Griffiths, K L Saunders, NHS West Midlands Regional Office, Birmingham, UK

Funding: West Midlands Public Health Levy.

Conflicts of interest: none.

\section{REFERENCES}

1 Faculty of Public Health Medicine. Governance of the public health function. A position paper from the FPHM of the Royal Collages of Physicians of the United Kingdom. September 1999. FFHM Working Draft on Govenance. Version 3. Revised 7.9.99. http:// www.fphm.org.uk
2 Department of Health. The new NHS modern dependable. White Paper. 1997 http://www.official-documents.co.uk/document/doh/ newnhs/newnhs.htm

3 Paris JAG, McKeown KM. Clinical governance for public health professionals. J Public Health Med 1999;21:430-4.

4 Bhopal RS, Thomson RG, White M, et al. Audit of public health medicine: the northern region's approach. J Public Health Med 1993; 15:255-62.

5 Chappel D, Fernandes V. An audit of environmental health calls to a department of public health medicine. Public Health 1995;109:413-16.

6 Gair R, Lan LLC, McKee M et al. Criteria for audit of annual reports on the public health: Do they exist? J Public Health Med 1992;14:169-72.

7 Garvican L, Mayon-White R, Littlejohns P. Public health physicians who contribute to on-call communicable disease control duties: national comparative clinical audit by questionnaire survey. J Public Health Med 1999;21:447-52.

8 Joyce L, Radford G, Forrest D. The South West Thames Regional Health Authority approach to the method of audit in public health medicine. J Public Health Med 1991;13:307-1 1 .

9 Powell PV. An audit of the handling of medical negligence complaints by a health board. Health Bull (Edinb) 1995;53:196-205.

10 Department of Health. Clinical governance: quality in the new NHS. HSC 1999/065, 1999.

11 Department of Health. Public health, the National Health Service and social care: statement of responsibilities and accountabilities.??: Department of Health, 1995

12 Myers IB, Myers PB. Gifts differing: Consulting Psychologists Press, Palo Alto. 1980.

13 Belbin RM. Management teams: why they succeed or fail. London: Heinemann Professional Publishing, 1981.

14 Health Act 1999. (http://www.legislation.hmso.gov.uk/acts/acts 1999/ 19990008. htm)

15 The Caldicott Committee. Report on the review of patient-identifiable information. NHS Executive, December 1997. http://www.doh.gov.uk/ confiden/crep.htm

16 NHS Executive. Implementing the recommendations of the Caldicott report. HSC 1998/089, 1998.

17 Department of Health. Shifting the balance of power within the NHS, securing delivery. July 2001 (http://www.doh.gov.uk/

shiftingthebalance/shiftingthebalance.pdf) 